\title{
Fragmentation Rate of Cementite Lamellas in Nanopearlite
}

\author{
JERZY STODOLNY, ${ }^{1}$ ADAM GOLASZEWSKI $(i),{ }^{1,2,3}$ \\ and ANNA ŁOTAREWICZ ${ }^{1}$ \\ 1.-REMIX S.A., 66-200 Świebodzin, Poland. 2.-Faculty of Materials Science and Engineering, \\ Warsaw University of Technology, Warsaw, Poland. 3.-e-mail: adamgolaszewski@gmail.com
}

Creating a spheroidal microstructure in steel is one of the ways to design its properties. Such a structure can be obtained during annealing of the martensitic, bainitic, or pearlitic structure at the temperature lower than $\mathrm{A}_{1}$. Research presented in this article was conducted to examine the fragmentation rate of a nanometric pearlitic structure into spheroidite in which the lamellas of cementite had a thickness below $100 \mathrm{~nm}$. The scope of tests included the initial heat treatment of $\mathrm{C} 45$ steel rods, which was followed by spheroidizing. The heat treatment ensured strong fragmentation of pearlite. Metallographic examinations were performed with the use of scanning and transmission electron microscopes. Moreover, hardness measurements were performed. The obtained structures were examined in terms of cementite lamellas thickness and in terms of the amount of spheroidite after the annealing process below $\mathrm{A}_{1}$ temperature.

\section{INTRODUCTION}

The properties of steel are usually shaped through dedicated plastic processing and heat treatment. However, before applying such treatments, the spheroidizing process is commonly used. During this process, the initial microstructure is created. It can affect the material's susceptibility to plastic working, and it may lead to homogenization of the structure. The latter may enable obtaining the maximum mechanical properties after the heat treatment process. The spheroidite structure is formed during the process of steel heating at a temperature lower than $\mathrm{A}_{1}$ and can be obtained in two ways:

- It may be created from a supersaturated solution during martensite tempering or during the formation of bainite. This process is called a bottomup approach.

- It may occur during the fragmentation of cementite lamellas present in pearlite during longterm heating at the temperature below $A_{1}$. This process is called a top-down approach. In this case, the already existing cementite lamellas fragmentize at first into small plates and then into rods, and finally, the rods are fragmented into smaller particles that then undergo gradual rounding. ${ }^{1}$
This study focuses on the second way, i.e., fragmentation of the pearlitic structure. Therefore, the process of pearlitic transformation will be described below as it is an important factor in accelerating the process of spheroidization.

Within pearlite transformation, the austenite supercooling occurs with the increase in the cooling rate. It leads to the fragmentation of the pearlitic structure. ${ }^{2}$ During such a process, both cementite and ferrite lamellas are being refined. This phenomenon is used during the continuous cooling process or during isothermal transformation taking place in the "nose" of the TTT diagram, e.g., during the wire patenting. Different studies on the pearlitic structure show that the strength of steel elements, which contain it, increases with the increase in supercooling. ${ }^{3}$ The formation of the pearlitic structure is a complex problem; therefore, the parameters of heat treatment should be selected carefully as they may significantly impact the mechanical properties through the refinement of the pearlitic structure. The pearlite structure seems to be a particularly interesting subject for such areas of steel applications as wire and railway rails. ${ }^{4-7}$ It is assumed in the literature that the following parameters are sufficient to define the pearlitic structure: ${ }^{8}$

- Interlamellar spacing in pearlite $(S)$

- Size of the prior austenite grain $(d)$ 


\section{- Size of pearlite colonies (blocks) $(P)$}

The aforementioned parameters allow the relationship between the properties of steel and the pearlitic structure to be precisely determined. Consequently, the yield point for steel with carbon content corresponding to the eutectoid point can be calculated from the formula:

$$
R_{\mathrm{e}}(\mathrm{MPa})=\frac{2.18}{\sqrt{S}}-\frac{0.40}{\sqrt{P}}-\frac{2.88}{\sqrt{d}}+52.30
$$

The conclusion is that the first part of the formula that contains the parameter determining the interlamellar spacing in pearlite has the greatest impact on the increase in the yield point. The smaller the interlamellar spacing is, the greater the increase is. A similar relationship occurs between interlamellar spacing and hardness. ${ }^{9}$ The hardness of the pearlitic structure for interlamellar spacing was tested in a range of about $120 \mathrm{~nm}$ to $470 \mathrm{~nm}$. Hardness values obtained for such distances were equal to 330 and $190 \mathrm{BHN}$. The relationship between these parameters was close to an exponential one in which hardness increased strongly with the decrease of the interlamellar spacing. Therefore, it may be assumed that obtaining pearlite with even smaller interlamellar spacings will allow for a further significant increase in hardness. This would mean, for example, a significant improvement (decrease) in the rails' wear during working and for the wires a further increase in their tensile strength.

The "interlamellar spacing" parameter ${ }^{10}$ is most frequently used to describe the pearlitic structure. The "cementite lamellas thickness" parameter is being used less frequently. ${ }^{11}$ The thicknesses of ferrite and cementite lamellas is not identical; therefore, all attempts to describe these structures by giving their thickness ratios seem inaccurate. Interlamellar spacing can vary significantly, from several dozen nanometers to over one micrometer. ${ }^{10}$ In the research conducted by G.V. Voort, the average interlamellar spacing in pearlite was equal to $333.4 \mathrm{~nm}$ and the largest distance measured between the lamellas was equal to $1130.2 \mathrm{~nm} .{ }^{10}$ However, the smallest interlamellar spacing was found by $\mathrm{Wu}$ and Bhadeshia. During the pearlitic transformation in a strong magnetic field, they produced an ultrafine pearlite with interlamellar spacing in the range of $50-100 \mathrm{~nm} .^{12}$

If pearlite is treated as a composite material made of a soft ferrite matrix reinforced with hard cementite lamellas, the final properties of such a composite will be determined through the form and distribution of the reinforcing phase. Therefore, it seems correct to observe and control the "cementite lamellas thickness" regardless of the observations of "interlamellar spacing."

To conclude, fragmentation of the pearlitic structure into spheroidite is a relatively long process. Therefore, the rate of fragmentation of pearlite lamellas and the possible ways of reducing the time of this process have been the subject of many research projects. Introducing plastic deformation could be one of the ways of accelerating this process. ${ }^{2,13}$ However, when pearlite spheroidization is discussed in different publications, there is information that the fragmentation rate of cementite lamellas during spheroidizing usually depends on the interlamellar spacing or less frequently on the cementite lamellas thickness. ${ }^{14,15}$ Nevertheless, given the fact that the proportion of cementite to ferrite in pearlite is not constant and can vary depending on the cooling rate, it seems more adequate to use lamellas thicknesses to describe the rate of their subsequent degradation during spheroidizing than the interlamellar spacing. The main objective of the research was to determine how much the spheroidizing process would be accelerated if the thickness of cementite lamellas in pearlite and the interlamellar spacing was reduced to the nanometer size. The results of the research conducted by Chattopadhyay and Sellars were used as the reference point for determining the time of pearlite spheroidization for eutectoid carbon steel. ${ }^{14}$

\section{EXPERIMENTAL}

In the research, commercial rods after threading were used. They were the size of M12 $\times 220 \mathrm{~mm}$, and they were made of C45 steel grade (1.0503), 8.8 class with the following chemical composition: $\mathrm{Fe}-0.47 \quad \mathrm{C}-0.22 \quad \mathrm{Si}-0.73 \quad \mathrm{Mn}-0.13 \quad \mathrm{P}-0.01$ $\mathrm{S}-0.18 \mathrm{Cu}-0.01 \mathrm{Al}-0.08 \mathrm{Cr}-0.02 \mathrm{Mo}-0.08 \mathrm{Ni}$ [wt.\%]. The chemical composition tests were carried out with the use of a Belec IN-SPECT spectrometer.

The tests included initial heat treatment of the rods, which were $110 \mathrm{~mm}$ long and their spheroidizing afterward. The purpose of initial heat treatment was to refine the grains in the rods made of $\mathrm{C} 45$ steel and to obtain the smallest possible pearlite. To achieve it, the bars were heated to the temperature of $850^{\circ} \mathrm{C}$ and then cooled in melted tin at $315^{\circ} \mathrm{C}$ at the rate that would allow for the bainite transformation to be avoided (Fig. 1). The process of cooling

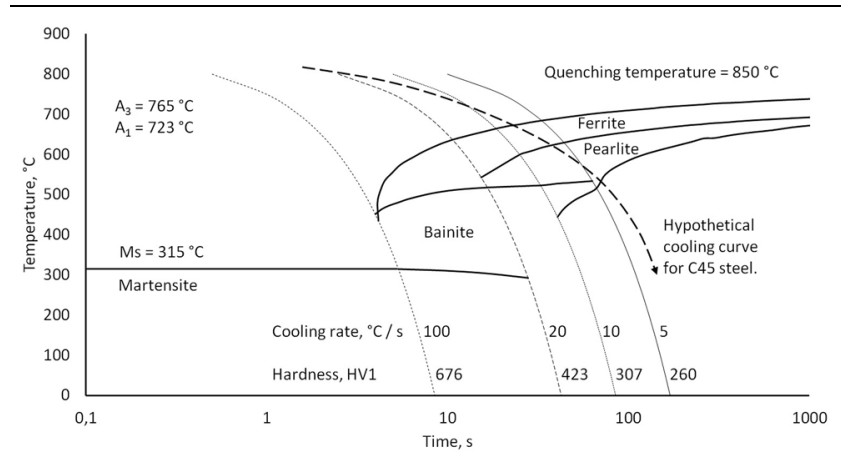

Fig. 1. CCT diagram for C45 steel based on the JMatPro program. The cooling rate in the experiment was close to $5^{\circ} \mathrm{C} / \mathrm{s}$. 
in molten tin was also applied to increase the cooling rate at higher temperatures to limit the volume fraction of ferrite in the structure. However, as the temperature dropped, the cooling rate decreased. It enabled a pearlitic structure without bainite or martensite to be created.

The spheroidizing process was carried out in an electrically heated laboratory furnace with a nitrogen atmosphere. Three different heating temperatures were used: $500^{\circ} \mathrm{C}, 600^{\circ} \mathrm{C}$, and $700^{\circ} \mathrm{C}$. Each temperature variant was applied for five different annealing times, i.e., $15 \mathrm{~min}, 1 \mathrm{~h}, 3 \mathrm{~h}, 9 \mathrm{~h}$, and $23 \mathrm{~h}$. After all heat treatments, hardness was examined with the use of a Vickers method with $0.5-\mathrm{kg}$ load.

Moreover, metallographic examinations were performed using scanning electron microscopy (SEM) and transmission electron microscopy (TEM). Microstructure investigations included the evaluation of grain size. The grain size assessment was carried out according to PN-EN ISO 643: 2005. It was conducted with the use of the intersection method. ${ }^{16}$ The analysis of the microstructures included also the measurements of cementite lamellas thickness and interlamellar spacing as well as the quantitative evaluation of spheroidite and of free ferrite in the samples subjected to spheroidizing. The measurements of lamellas thickness and the interlamellar spacing were made with the use of the Gimp 2.8 graphic program. The volume fraction of individual structural elements was determined by counting the nodes on the grid placed on the photo. ${ }^{17}$ The nodes appeared at the measured elements of the structure.

\section{TEST RESULTS}

\section{Examination of the C45 Steel Structure Before and After Initial Heat Treatment}

A characteristic feature of the material used for the tests is the ferritic-pearlitic structure with a very fine grain size. The average size of the prior austenite grain is $7 \mu \mathrm{m}$, which corresponds to grain size reference number 11 where the grain size varies from $2 \mu \mathrm{m}$ to $18 \mu \mathrm{m}$ (Fig. 2). After the initial

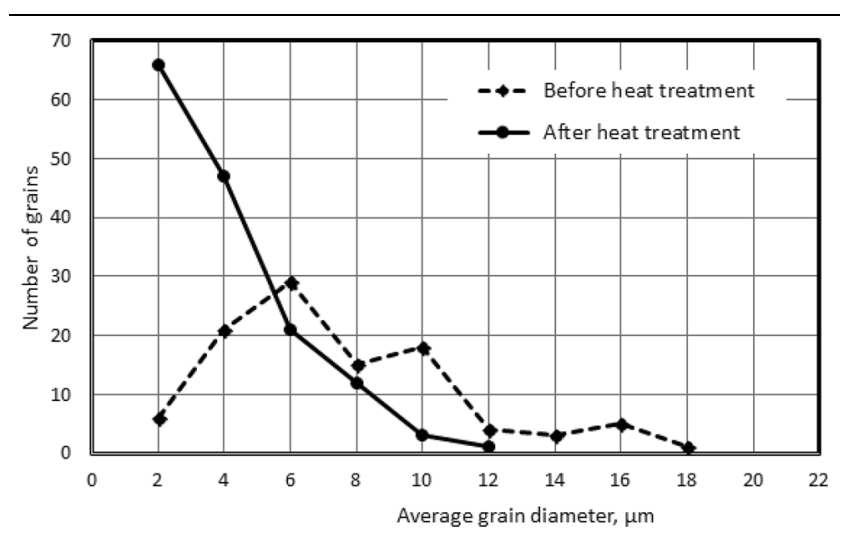

Fig. 2. Changing the grain size distribution as a result of the initial heat treatment. heat treatment, the grain size was reduced. The average diameter of the prior austenite grain is $3 \mu \mathrm{m}$. This corresponds to grain size reference number 13 . The range of the grain diameter distribution, which is between $2 \mu \mathrm{m}$ and $12 \mu \mathrm{m}$, has also been narrowed. The highest number of grains was observed for the smallest range, i.e., up to $2 \mu \mathrm{m}$. Before the heat treatment, the peak had been observed for the range of $6 \mu \mathrm{m}$.

The change in the amount of free ferrite was noticed when the microstructure images before and after preheat treatment were compared (Fig. 3). It was evident that the volume fraction of ferrite after the initial heat treatment was significantly lower due to the rapid cooling in a melted tin. The amount of free ferrite in this case was estimated to be $8.5 \%$, whereas before the initial treatment, the ferrite volume fraction was about $40 \%$. Strong supercooling of austenite led to a reduction in the amount of ferrite in the structure, and consequently, it contributed to its homogenization. After the initial heat treatment, hard cementite particles were more evenly distributed in a soft ferrite matrix.

The initial heat treatment leads also to the fragmentation of pearlitic lamellas and to the reduction in the interlamellar spacing (Fig. 3). The TEM study image shows that those parameters are of nanometric size (Fig. 4). Before the initial heat treatment, the thickness of the cementite lamellas varied from about $70 \mathrm{~nm}$ to $150 \mathrm{~nm}$ and the thicker lamellas occurred locally (Fig. 5). The maximum thickness of $\mathrm{Fe}_{3} \mathrm{C}$ lamellas was found to be $428 \mathrm{~nm}$. However, the interlamellar spacing oscillates around the dominant at the level of around $300 \mathrm{~nm}$. The reduction in grains that stemmed from the pretreatment occurred together with a change in the interlamellar spacing of cementite and in the thickness of the $\mathrm{Fe}_{3} \mathrm{C}$ lamellas (Fig. 5). In both cases, the results are shifted into the nanometer direction. Cementite lamellas with thickness usually in the range of $20-40 \mathrm{~nm}$ were obtained and the interlamellar spacing was in the range of 50$130 \mathrm{~nm}$. Because of that, the structure was called nanopearlite.

The hardness of C45 steel after initial heat treatment is slightly lower than steel in the state of delivery. Higher hardness in the initial state is likely to stem from the plastic processing in which the threads were formed.

\section{Structure Examination After Spheroidizing and Quantitative Assessment of Spheroidite}

After preliminary heat treatment in which the nanopearlitic structure was made, C45 steel was subjected to the spheroidizing processes. During the quantitative analysis of a microstructure before spheroidizing, it was estimated that after initial heat treatment, the structure consisted of finegrained pearlite mainly and free ferrite took up $8.5 \%$ of the volume fraction. In the examined 


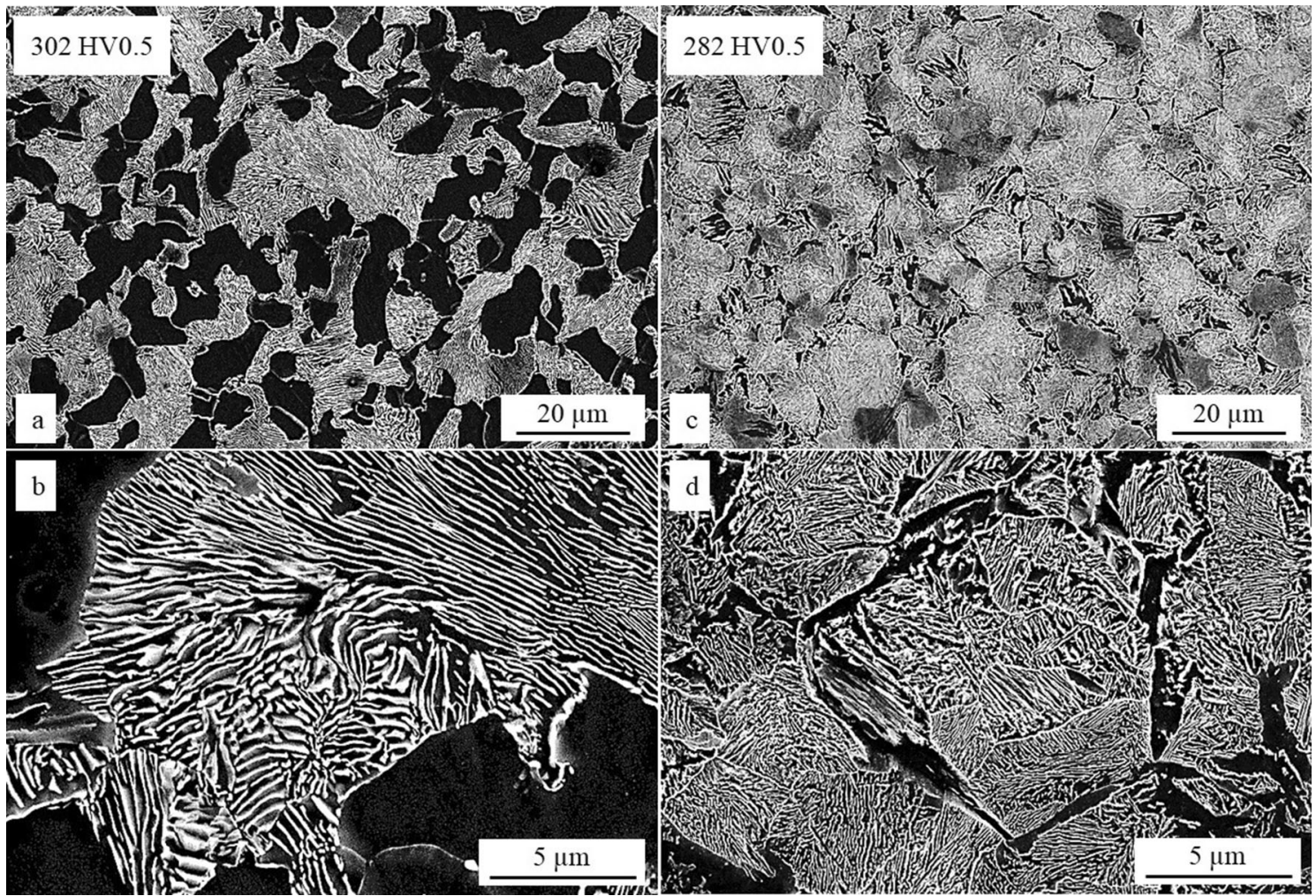

Fig. 3. C45 steel microstructure refinement due to preliminary heat treatment with tin cooling. a, b Before pre-treatment; $\mathbf{c}, \mathbf{d}$ after pre-treatment.

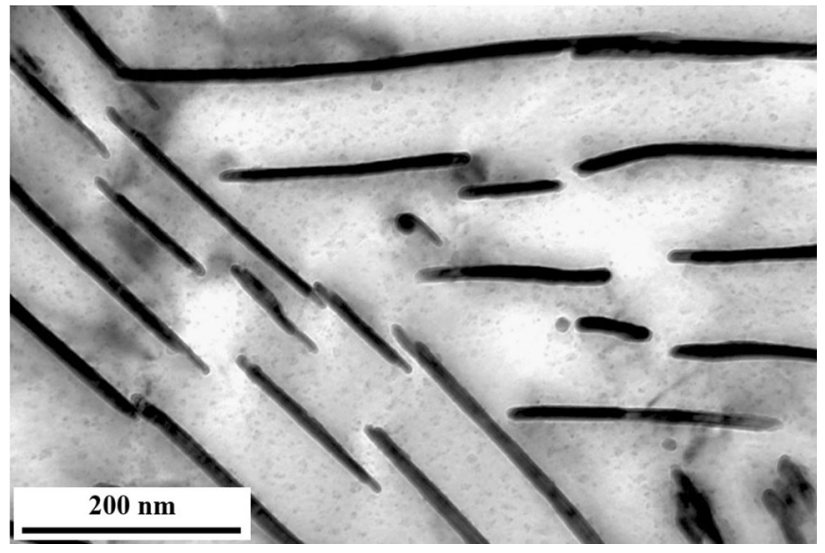

Fig. 4. Example of a nanopearlitic structure observed in TEM studies.

structure, there were small areas with spheroidite. Their volume fraction was about 2.7\%. During spheroidizing, the amount of free ferrite as well as the amount of spheroidite are the components of the structure that are not subject to quantitative changes. Therefore, they were marked in the lower part of the chart with fixed-value lines (Fig. 6). The examples of such structures after spheroidizing are shown in Fig. 7.

The impact of the changes occurring in time is visible for all the annealing temperatures (Fig. 6). However, for the temperature of $500^{\circ} \mathrm{C}$, the changes are insignificant. Moreover, after heating for $23 \mathrm{~h}$, the volume fraction of spheroidite increased only up to $11 \%$, whereas for the same time but at $600^{\circ} \mathrm{C}$, pearlite was completely fragmented into spheroidite. Such a result is reflected in the hardness measurements. After spheroidizing at $500^{\circ} \mathrm{C}$, hardness is higher and equal to 235 HV0.5. Whereas, after annealing at $600^{\circ} \mathrm{C}$, it is equal to $210 \mathrm{HV0.5}$. In contrast, fragmentation of pearlite, which occurred within $1 \mathrm{~h}$ of spheroidizing at $700^{\circ} \mathrm{C}$, was almost total. After this process, hardness was at a similar level as hardness of steel after 23-h-long spheroidizing at $600^{\circ} \mathrm{C}$. Moreover, the microstructures in both cases were also similar. During the longer spheroidization process at $700^{\circ} \mathrm{C}$, the cementite lamellas disappeared completely. Hardness dropped down to 176 HV.5 after 23-h-long annealing. Test results, i.e., the very short time of fragmentation of cementite nanolamellas, was the most surprising fact revealed by the authors during the experiments.

It may be noticed that for higher annealing temperatures, the impact of changes is more intense at the first stage of heating. The percentage of pearlite falls below $10 \%$ after only $15 \mathrm{~min}$ for the temperature of $700^{\circ} \mathrm{C}$ ( $\left.211 \mathrm{HV} 0.5\right)$, whereas for the temperature of $600^{\circ} \mathrm{C}$, after $3 \mathrm{~h}(235 \mathrm{HV} 0.5)$.

\section{DISCUSSION}

This paper focuses on C45 hypoeutectoid steel. For this type of steel, a typical structure after the normalizing annealing process is a ferritic-pearlitic 

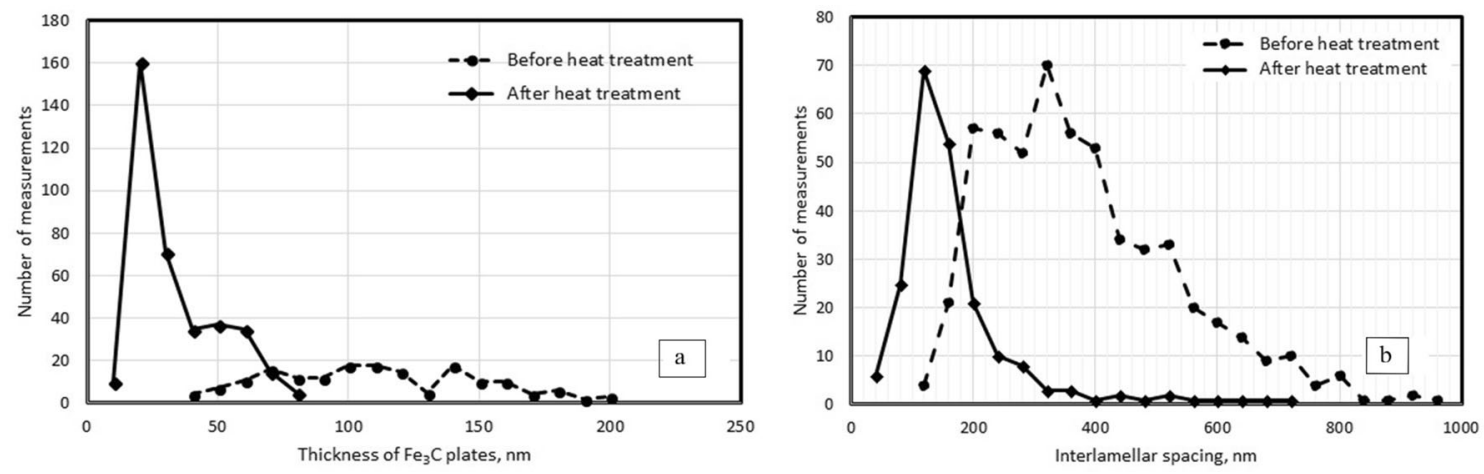

Fig. 5. Change in the lamellas thickness $\mathbf{a}$ and the interlamellar spacing of cementite $\mathbf{b}$ due to initial heat treatment.

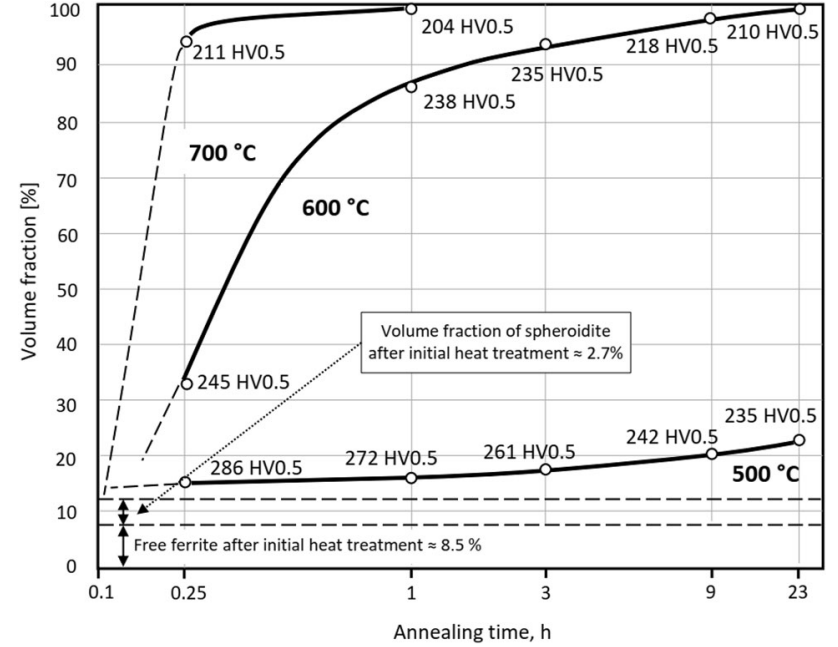

Fig. 6. Spheroidization rate of nanopearlite at $500^{\circ} \mathrm{C}, 600^{\circ} \mathrm{C}$, and $700^{\circ} \mathrm{C}$. The amount of free ferrite (about $8.5 \%$ ) as well as the amount of spheroidite created during the initial heat treatment $(2.7 \%)$ are the components of the structure that are not subject to quantitative changes during spheroidizing.

one. This structure contains about $40 \%$ of free ferrite and about $60 \%$ of pearlite, and it is obtained if the cooling process after annealing is slow. The contribution of both structural components changes if the cooling rate increases.

However, it is possible to reduce the proportion of ferrite as the cooling rate in the area of ferrite and pearlite formation increases. This will result in reduction in the average concentration of carbon in pearlitic colonies. ${ }^{18}$ Theoretical carbon content in pearlite can be determined through extrapolation of the equilibrium lines between austenite and ferrite and between austenite and cementite (Hultgren's extrapolation). Houin et al. ${ }^{18}$ showed that the structure composed of pearlite can be only created in carbon steels with a carbon content of $0.2 \%$ to $0.8 \%$.

In this study, the cooling process was performed in liquid tin, which accelerated the cooling rate at higher temperatures, and it reduced the formation of ferrite. However, the cooling rate dropped when it was getting closer to the temperature of the tin bath. This resulted in the formation of a pearlitic structure without bainite and martensite. Finally, about $8.5 \%$ of free ferrite formed in the structure, and the rest of it was a mixture of ferrite and cementite. This mixture contained about $2.7 \%$ volume fraction of spheroidite, and the rest was pearlite.

According to the Hall-Petch relation, the yield strength of steel increases with the increase in the refinement of the structure. Therefore, the manufacturing process of a product should be carried out in a way that leads to the refinement of the microstructure. This should happen irrespective of the type of heat treatment applied as long as it is intended to improve strength. Normalizing annealing is commonly used for carbon types of steel. It leads to the grain refinement and, thus, to the improvement in the properties. However, it is known that if the very fine grains are formed before normalizing annealing, e.g., due to heat treatment, thermomechanical, or other methods, normalizing annealing will lead to further grain refinement. The type of steel that was examined had a fine-grained microstructure when it was delivered. However, the preliminary process that was carried out led to its further refinement (Fig. 2). A similar effect is observed during the normalizing annealing process. According to the standard, the applied heat treatment can be compared to the normalizing annealing process because it leads to the refinement of a microstructure but it does not change its structural components. ${ }^{19}$

Accelerated cooling in the range of pearlitic transformation resulted in a strong reduction in the interlamellar spacing as well as in the reduction in the thickness of the $\mathrm{Fe}_{3} \mathrm{C}$ lamellas. Consequently, the cementite lamellas with thickness in the range of $20-40 \mathrm{~nm}$ and interlamellar spacing in the range of 40-200 nm were obtained.

The fragmentation process of cementite particles into spheroidite is widely known, and typically it requires hundreds of annealing hours. ${ }^{14}$ The novelty of this work is that through the experimental methods, it was proved that the fragmentation time of cementite can be dramatically shortened if the 


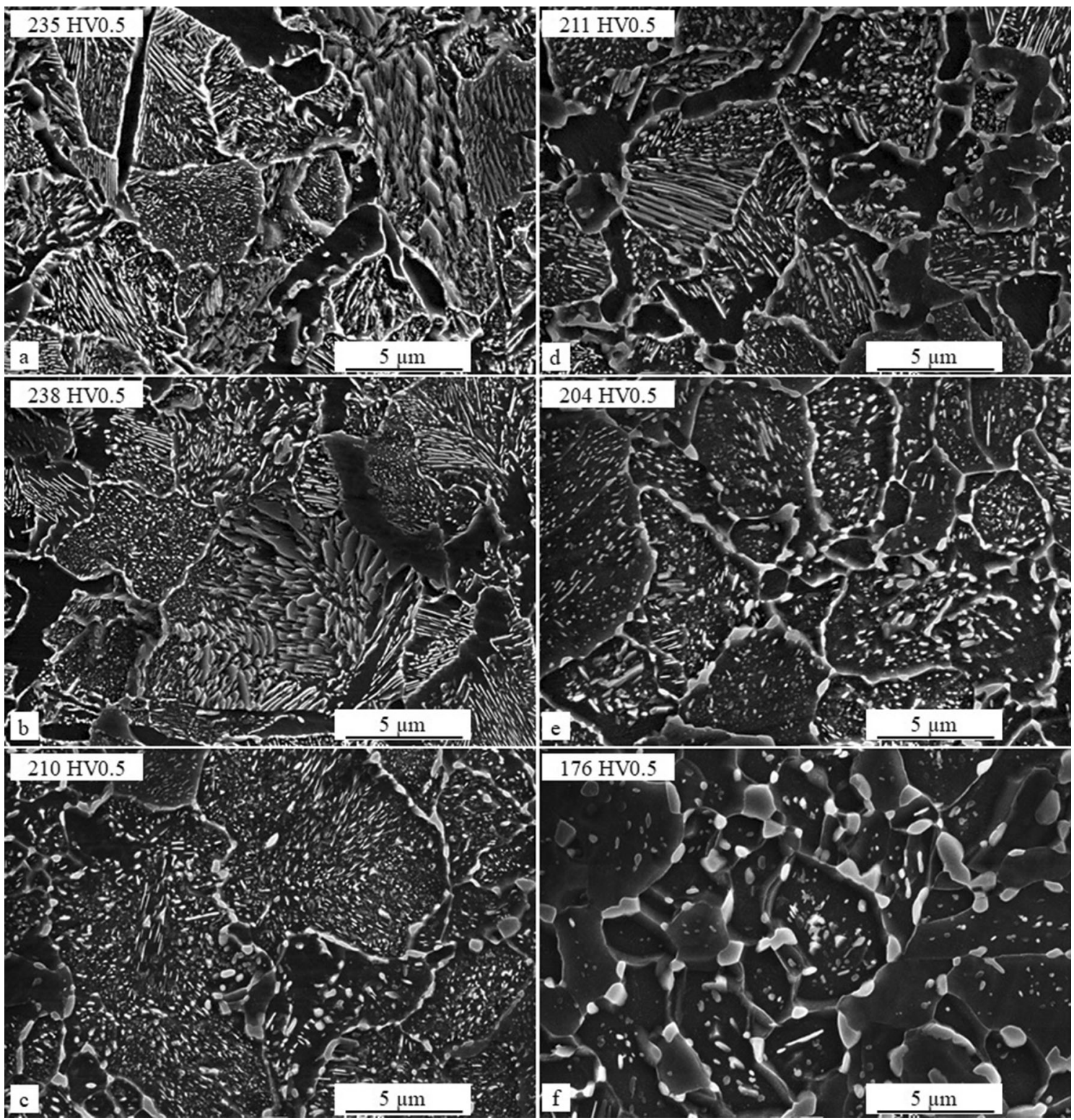

Fig. 7. Examples of microstructures and its hardness after spheroidizing at various temperatures. a $500^{\circ} \mathrm{C}$ for $23 \mathrm{~h}, \mathbf{b} 600^{\circ} \mathrm{C} / 1 \mathrm{~h}, \mathbf{c ~} 600^{\circ} \mathrm{C} / 23 \mathrm{~h}$, d $700^{\circ} \mathrm{C} / 15^{\prime}$, e $700^{\circ} \mathrm{C} / 1 \mathrm{~h}$, f $700^{\circ} \mathrm{C} / 23 \mathrm{~h}$.

thickness of cementite lamellas as well as interlamellar spacing were reduced to nanoscale. In the experiment described in this paper, the fragmentation time of the nanopearlitic structure into spheroidite at $700^{\circ} \mathrm{C}$ is about $1 \mathrm{~h}$. The experiment was conducted for cementite lamellas with a thickness in the range of 20-40 $\mathrm{nm}$ and interlamellar spacing in the range of $40-200 \mathrm{~nm}$. Chattopadhyay and Sellars ${ }^{14}$ showed that the fragmentation of pearlite led to the shorter time of the spheroidizing cycle. It was shown in this paper that the initial nanopearlite structure enables spheroidizing to be conducted in an extremely short time (Fig. 8). The results showing the fragmentation rate of the cementite lamellas refer to a spheroidizing temperature equal to $700^{\circ} \mathrm{C}$. Since the spheroidization process is a diffusion one, it is obvious that lowering the temperature will lead to an increase in the fragmentation time of the lamellas (Fig. 6).

It is worth saying that the Chattopadhay and Sellars tests were carried out with the use of steel containing $0.74 \% \mathrm{C}$. However, the type of steel examined within this project contained $0.45 \% \mathrm{C}$. Therefore, the comparison of different pearlite fragmentation rates presented in their paper did not take into account the possibility of differences in the dissolution rate of the $\mathrm{Fe}_{3} \mathrm{C}$ lamellas resulting from different levels of carbon in steel.

To conclude, a homogeneous structure with a limited volume fraction of soft free ferrite was finally obtained as a result of the performed preliminary treatments. In this structure, hard 


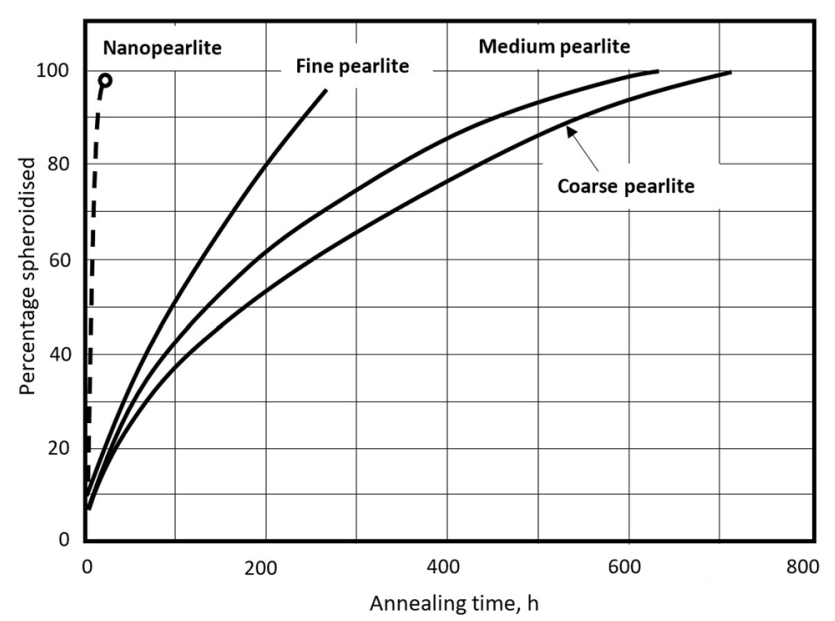

Fig. 8. Spheroidization rate of nanopearlite (dashed line-own research). Continuous lines_curves drawn according to Chattopadhyay and Sellars data. ${ }^{14}$

particles of cementite in the form of spheroidite were evenly distributed in the volume of the material and this may provide a more advantageous set of mechanical properties. This structure was obtained as a result of preliminary heat treatment and of a very short spheroidizing process.

\section{CONCLUSION}

1. Nanopearlite was obtained in C45 steel. To achieve it, the smallest possible initial structure had to be chosen as well as a relatively high cooling rate, which was possible to obtain during preheat treatment. Nanopearlite is a structure with the size of cementite lamellas in the range of $20-40 \mathrm{~nm}$ and the space between the $\mathrm{Fe}_{3} \mathrm{C}$ lamellas in the range that overlaps the nanoscale, i.e., in the range of $40-200 \mathrm{~nm}$.

2. The initial heat treatment allowed a relatively small amount of the free ferrite to be obtained in $\mathrm{C} 45$ steel after annealing at $850^{\circ} \mathrm{C} / 20 \mathrm{~min}$. This ensures greater homogeneity of the structure.

3. The nanopearlitic structure is subjected to very rapid spheroidizing (about an hour) during the annealing process conducted below $\mathrm{A}_{1}$. This is a great advantage from the perspective of the industrial practice.

\section{ACKNOWLEDGEMENTS}

The authors would like to thank the NCBiR and the REMIX SA for their financial support with the research. The results of the experiments revealed in this article were obtained within the project
POIR.01.01.01-00-1637/15. We would also like to thank MA Dorota Pietrzyk for helping with translation.

\section{OPEN ACCESS}

This article is distributed under the terms of the Creative Commons Attribution 4.0 International License (http://creativecommons.org/licenses/by/4.0/), which permits unrestricted use, distribution, and reproduction in any medium, provided you give appropriate credit to the original author(s) and the source, provide a link to the Creative Commons license, and indicate if changes were made.

\section{REFERENCES}

1. P. Matusiewicz, J. Augustyn-Nadzieja, A. Czarski, and T. Skowronek, Arch. Metall. Mater. 62, 241 (2017).

2. J. Arruabarrena, P. Uranga, B. López, and J.M. RodriguezIbabe, Paper presented at the Proceedings of the Materials Science \& Technology Conference and Exhibition 2011, vol. 1 (2011), p. 698.

3. J. Toribio, B. González, J.C. Matos, and F.J. Ayaso, Frattura Ed Integrità Strutturale 30, 424 (2014).

4. D. Grygier, Nanokrystalizacja cementytu $w$ stalach perlitycznych stosowanych na druty kordowe do opon (Wrocław: Oficyna Wydawnicza Politechniki Wrocławskiej, 2017).

5. M. Buława and K. Semrau, Zeszyty Naukowo-Techniczne Stowarzyszenia Inżynierów i Techników Komunikacji w Krakowie. Seria: Materiały Konferencyjne, vol. 3 (2013), pp. $48-59$.

6. S. Nishida, S. Yamasaki, H. Demachi, N. Muroga, S. Ohashi, K. Nakamura, M. Kosaka, N. Komiya, and S. Sahara, U.S. Patent US20110284139 (2011).

7. G. Krauss, Steels-Processing, Structure, and Performance, 2nd ed. (Ohio: ASM International, 2007).

8. J.M. Hyzak and I.M. Bernstein, Metall. Trans. A 7A, 1217 (1976).

9. P. Clayton and D. Danks, Wear 135, 369 (1990).

10. G.F. Vander Voort, Prakt. Metallogr. 52, 419 (2015).

11. B.E. O'Donnelly, R.L. Reuben, and T.N. Baker, Met. Technol. 11, 45 (1984).

12. K.M. Wu and H.K.D.H. Bhadeshia, Scr. Mater. 67, 53 (2012).

13. D. Hauserova, J Dlouhy, and Z. Novy, Paper presented at the Proceedings of the 21st International DAAAM Symposium (2010).

14. S. Chattopadhyay and C.M. Sellars, Metallography 10, 89 (1977).

15. R. Cryderman, B. Whitely, and J. Speer, Paper presented at the Proceedings of the International Federation of Heat Treating and Surface Engineering, ASM, 18-21 April, 2016.

16. PN-EN ISO 643:2013-06, Stal-Mikrograficzne określanie wielkości ziarna.

17. J. Ryś, Stereologia Materiałów (Kraków: Fotobit Design, 1995).

18. P. Houin, A. Simon, and G. Beck, Trans. Iron Steel Inst. Jpn. 21, 726 (1981).

19. PN-EN ISO 4885:2018-05, Stopy żelaza-Obróbka cieplna-Terminologia.

Publisher's Note Springer Nature remains neutral with regard to jurisdictional claims in published maps and institutional affiliations. 